\title{
Motivational Barriers and Resources for Physical Activity Among Older People
}

\author{
Verena Klusmann and Nanna Notthoff
}

\subsection{Introduction}

Imagine wanting to assist an older person in becoming physically active or in increasing their activity to a health-enhancing level. As you begin, you realise that physical activity is neither part of his or her self-concept (i.e., he or she does not self-identify as an "active person") nor are there significant exercising role models in his or her past or present social environment (e.g., no friends or relatives of the same age exercise regularly). Further, you worry that the person may feel invulnerable to the risk of developing a health problem and may not be convinced that exercise entails any benefits at all. Above all, your target person may think that ageing comes with inevitable physical and social losses. All of this seems a bit exaggerated? On second thought, it might not be too unrealistic. The large number of inactive people is evidence for these motivational barriers. For our fictitious individual, hardly any other idea would seem more far-fetched than beginning to be more physically active. Any personal competencies like exercise skills or the necessary physical

\author{
V. Klusmann $(\bowtie)$ \\ Department of Psychology, Psychological Assessment \& Health Psychology, \\ University of Konstanz, Konstanz, Germany \\ Department of Human and Health Sciences, Institute for Public Health \\ and Nursing Research, Division for Health Promotion \& Prevention, \\ University of Bremen, Bremen, Germany \\ N. Notthoff \\ Department of Psychology, Humboldt University Berlin, Berlin, Germany
}


conditions would be irrelevant, and considerations of fostering self-efficacy (see Chap. 12) or implementation strategies (see Chap. 14) would be premature and futile. Thus, this chapter deals with central concepts of motivational barriers and resources for physical activity with special attention to older adults. After introducing and defining each of the constructs, corresponding empirical evidence will be discussed, and finally, practical implications will be presented as appropriate.

\subsection{Self-Identity}

Self-identity refers to being situated in a specific role (Stets and Burke 2003). According to Identity Theory, people's goals are based on their identities, and people strive to maintain consistency between identity and behaviour in pursuing their goals (Gecas and Burke 1995). The mechanisms for how this happens can be drawn from Social Cognitive Theory (see Chap. 11). For example, a person who identifies as an exerciser could have high levels of exercise-related self-efficacy (belief to be able to exercise, even in the face of obstacles), a reliable predictor of behaviour (see Chap. 12).

People who seriously pursue athletic endeavours tend to identify with these activities. This was demonstrated in a study of master cyclists (35-69 years) who described cycling as part of their identity that distinguished them from other people (Appleby and Dieffenbach 2016). One does not have to be an athlete to identify as an "exerciser" or physically active person. Among participants (58-95 years) in exercise classes in an assisted living facility, many people agreed that physical activity was part of their identity. The more they agreed, the more active they were and the more they intended to continue their activities in the future (Strachan et al. 2010).

The relationship between exercise identity and physical activity engagement seems to be bi-directional. In a sample of members of a 24-hour fitness facility (18-94 years), the more people exercised, the more they perceived physical changes in their bodies, which in turn led them to identify more as exercisers (Mullen 2011). This was true for the entire age range. An external prompt may be effective to jumpstart this process. Hardcastle and Taylor (2005) showed that middle-aged and older adults (43-77 years) who had received a prescription from their general practitioner to participate in a tenweek exercise program to improve their general fitness or health began to form an exercise identity. Contributing factors were physical activities' becoming part of people's routine, experiencing physical activity as meaningful and as a way to feel accomplished, and making social connections. Thus far, intervention studies aimed at modifying physical activity identity in older 
adults and affecting their behaviour have not been conducted. In younger adults, findings on whether changes in identity also result in changes in behaviour seem to be mixed according to a recent review (Rhodes et al. 2016).

From a provider's perspective, the idea of how well exercise aligns with older adults' identity also seems to be important. The degree to which exercise fits with older adults' identity was one of the main factors determining whether or not older adults took up exercise according to interviews with instructors (Hawley-Hague et al. 2016). The instructors stated that family members and health professionals sometimes undermined the process of physical activities' becoming integrated into older adults' identity when they communicated their belief that exercise was not suitable beyond a certain age. Thus, in considering whether and how physical activity becomes part of older adults' identity, one also has to take into consideration views of ageing (cf. Whaley and Ebbeck 2002). Ageing is often viewed as associated with physical limitations, which may prevent physical activity from becoming part of an older adult's identity (see also paragraphs 13.4 on subjective norms and 13.5 on self-perceptions of ageing).

\subsection{Autonomous Versus Controlled Motivation}

Unlike other concepts of motivation, Self-Determination Theory (SDT) focuses on type, rather than amount of motivation (Deci and Ryan 2008). In its original form (see also Chap. 11), SDT differentiated between intrinsic and extrinsic motivation with intrinsic motivation coming from within a person (e.g., an activity is performed for enjoyment) and extrinsic motivation being a result of external pressures (e.g., an activity is performed for a reward). People's motivation for behaviour can shift on a continuum from autonomous to controlled motivation, comprising external and so-called introjected regulation, the latter referring to internalised rewards and punishments (Deci and Ryan 2008).

Only recently, has SDT been applied to studying physical activity of older adults. The idea that higher levels of autonomous motivation for physical activity are associated with greater activity participation was confirmed in several quantitative and qualitative studies. Ferrand et al. $(2012,2014)$ showed that the amount of physical activity older enrolees (63-89 years) in a French activity program engaged in depended on their motivational profile. Participants in the cluster characterised by a higher degree of autonomous motivation were more active than those in the cluster characterised by a somewhat higher degree of controlled motivation. SDT motivational profiles 
also seem to predict whether or not people maintain or take up physical activity in retirement (Beck et al. 2010).

SDT has successfully been used as a basis for the design of interventions aimed at promoting physical activity in older adults. Thus far, it is unclear whether it is superior to other theoretical models. Friederichs et al. (2015) showed that both an SDT-based intervention and a traditional condition based on several other theories (Theory of Planned Behaviour, Social Cognitive Theory, Self-regulation Theory, and Transtheoretical Model; see Chap. 11) and involving tailored advice increased physical activity more than the waitlist control condition (18-70 years). The SDT-based intervention was more effective for promoting total minutes of activity, whereas the traditional approach was more effective for increasing the number of days on which participants engaged in at least 30 minutes of activity (Friederichs et al. 2015). In encouraging sedentary older adults to walk more, an SDT-based approach was superior to simply referring people to an exercise class or providing them with a structured walking program (Van Hoecke et al. 2014).

Interventions to date have sought to increase autonomous motivation by targeting the three psychological needs-autonomy, competence, and relatedness - that are proposed to be the underlying mechanisms. Van Hoecke et al. (2014) confirmed that individual counselling sessions were successful in promoting the satisfaction of the three needs and that participants experienced gains in autonomous motivation as a result. The relevance of the three needs for autonomous motivation was also recognised by participants themselves in another study (Lee et al. 2016). Interviews with participants of a French activity program showed that having an opportunity to assist with leading a program (autonomy) and feeling socially connected with other group members (relatedness) increased autonomous motivation. Concerns about age-related physical limitations, in contrast, led to higher controlled motivation (Ferrand et al. 2014).

However, the satisfaction of psychological needs can also be cited as a reason for being sedentary. Although one of the main motivations for remaining physically active in retirement was being part of a social group, inactive retirees found other ways to satisfy their need for relatedness. Furthermore, not fitting in with an exercise group was also one of the reasons why people discontinued physical activity. The importance of these psychological needs may differ between men and women. Relatedness seems to be more significant for women than for men. It should also be recognised that the association between psychological needs, motivational profiles, and physical activity is multi-directional. For example, increases in physical activity participation can lead to feelings of achievement and competence (Beck et al. 2010; Solberg et al. 2012). 


\subsection{Subjective Norms}

The idea that subjective norms influence behaviour has been incorporated in several theories of health behaviour change (see Chap. 11). The term subjective norm refers to the likely or anticipated pressure from social partners such as family members and friends, but also health professionals to perform a behaviour and the motivation to give into this pressure. In other words, a person's subjective norm is his or her impression of what important social partners believe the person ought to do. Importantly, subjective norms should be distinguished from social norms, which are normative beliefs that are present in society as a whole.

Although subjective norms as a construct within the Theory of Planned Behaviour (see Chap. 11) have been broadly applied to understanding the uptake and maintenance of physical activity and designing intervention studies aimed at promoting it, few studies have included older adults, as documented in a recent review (Koeneman et al. 2011). Only 1 of the 30 included studies examined the influence of subjective norms on older adults' attendance in a physical activity program.

From the limited available evidence, it appears that subjective norms can be useful for predicting older adults' intentions to be physically active; however, they do not tend to reliably predict behaviour. For example, subjective norms predicted the intention of older adults aged 65-90 years enrolled in an exercise program to attend classes regularly (Lucidi et al. 2006). Actual class attendance was unrelated to participants' subjective norms. Likewise, subjective norms predicted older women's intention to meet the World Health Organization's (WHO) recommendations for aerobic physical activity (150 minutes of moderate activity per week or 75 minutes of vigorous activity per week), but not whether they actually met these recommendations (Vallance et al. 2011). The construct of subjective norms is not the only one of the Theory of Planned Behaviour components that only tends to predict older adults' intention to be physically active, but not their behaviour (Dean et al. 2007).

Findings regarding which factor in the Theory of Planned Behavioursubjective norms, perceived behavioural control, or attitudes (see paragraph 13.7 on outcome expectancies) - best predicts intention to be active or actual activity are mixed. Two studies showed that although the Theory of Planned Behaviour as a whole predicted older adults' intention to be physically active, when the three factors were considered separately, only perceived behavioural control was relevant (Brenes et al. 1998; Galea and Bray 2006). 
In sum, the available evidence suggests that subjective norms could be useful for predicting the intention of older adults who are already affiliated with a physical activity program to attend program sessions regularly. It remains unclear whether subjective norms can explain shortfalls of activity in sedentary older adults. Interventions aimed at changing subjective norms and the effects of such changes on physical activity intention and behaviour seem to be lacking, possibly because existing observational studies have documented that subjective norms do not reliably predict actual behaviour. If subjective norms were the target in a behavioural intervention, measures should be taken to reduce the intention-behaviour gap (see Chap. 14).

\subsection{Self-Perceptions of Ageing}

Recent research has demonstrated that how people view their own and others' ageing has the potential to determine whether they engage in health-promoting behaviours (for an overview see Miche et al. 2015). People, who in midlife associated their own ageing with fewer negative changes, lived a full 7.6 years (median) longer than their peers (Levy et al. 2002). When compared with recent data (Nusselder et al. 2009) on increased life expectancy through not smoking (4.3 years for men, 4.1 years for women) or high levels of physical activity (3.5 years for men, 3.4 years for women), these "added years" that seem to depend on ageing self-perceptions are especially impressive.

Levy (2009) postulates that age stereotypes exert their influence on health, well-being, and longevity through having pertinent behavioural consequences like healthy practices such as participating in exercise (see Levy and Myers 2004). That age expectations of decline seem to act as a barrier to physical activity has been shown by large-scale surveys (Meisner et al. 2013; Sarkisian et al. 2005). The study by Meisner et al. (2013) indicated a "matching effect," that is, more positive ageing-related expectations regarding physical health (but not expectations about mental health or cognitive function) were associated with strenuous sport and recreational physical activities in those adults (41-97 years) without functional limitations. Consequentially, negative expectations may make people think that they are unable to engage in strenuous activities due to their advanced age and, subsequently, they may dis-identify (see paragraph 13.2 on self-identity) and disengage from these activities.

Studies using data from the German Aging Survey showed that positive images of ageing increased sports participation in middle-aged adults (40-64 years) and leisure-time walking in older adults (65-85 years; Wurm et al. 2010). Given a positive view on ageing, even older people in poor health 
walked as regularly as their healthy peers. Shedding some light on underlying mechanisms, Wurm et al. (2013) found that after a serious health event, older people were inclined to utilise productive strategies like selective optimisation and compensation (see Chaps. 14 and 15) if they did not equate ageing with physical losses. Those with negative images of ageing, in contrast, did less for their health, which eventually resulted in lower life satisfaction and worse subjective health.

Interventions fostering a positive view on ageing in older adults may be successful in not only improving self-perceptions of ageing, but also increasing physical activity. In one intervention, images of older adults were changed by correcting false beliefs about ageing and teaching participants to identify and modify automatic counterproductive thoughts (Wolff et al. 2014). Positive age stereotypes may even be strengthened via subliminal priming (Levy et al. 2014). Evoked mastery experiences through becoming physically active, in turn, may help to buffer otherwise worsened ageing evaluations (Klusmann et al. 2012). This is in line with Meisner and colleagues' (2013) assumption that interventions to promote realistic ageing expectations regarding physical health should be particularly effective for increasing physical activity in older adults; they combat fatalistic thinking and stereotype-congruent disengagement. On a societal level, fostering positive intergenerational interactions, education about age and ageing, and changing media portrayals of older people have been suggested (Kotter-Grühn 2015). Interventions could also make use of the matching effect and use role models to combat stereotypes of ageing (Horton 2010).

\subsection{Risk Perceptions}

Perceptions of risk are crucial for motivating people to adopt protective behaviours like physical activity, especially in old age (Renner et al. 2007; Schwarzer and Renner 2000). Commonly, it is assumed that threat appraisals result from perceived susceptibility or vulnerability and severity of disease (Stretcher et al. 1997; van der Pligt 1998).

Experts commonly judge and compare risk factors by combining the likelihood of occurrence and the severity of adverse outcomes (Fischhoff et al. 2000; Slovic 2000). Communicating a health threat in a way common in public health campaigns aimed at disease prevention can only solve part of the problem, however (Hamilton and Lobel 2015). In order to take protective action, people need to not only be aware of a risk in general, but they need to feel personally at risk (Schwarzer 2008). Lay people's assessments are a func- 
tion of the triggered affective responses (e.g., worry and perceived dread) and the familiarity and estimated controllability of a health threat (Slovic 1987; Slovic et al. 2005). Motivating people for proper action might work best if one tackles anticipatory emotions, possibly by using affect-rich images and narratives (Sheeran et al. 2014; Slovic and Peters 2006).

Both the adequacy and the adaptiveness of lay people's judgements have been subject to controversial debates (for an overview see Renner and Schupp 2011). It is an often replicated finding that people accept high-risk health information to a lesser degree than low-risk information, often referred to as self-defensive bias (Ditto 2009; Helzer and Dunning 2012; Van 't Riet and Ruiter 2013). However, a lack of reassurance after receiving low-risk feedback has also been observed (e.g., Gamp and Renner 2015). The Cue-Adaptive Reasoning Account (Renner 2004) explained how people reasonably invest resources to scrutinise negative and unexpected risk information, what prevents them from both an unnecessary investment and a rash termination of already-taken protective actions (Renner and Schupp 2011).

Comparing participants under the age of 31 years with older adults (31-84 years) from a German sample revealed that the perception of risk significantly predicted the intention for protective behaviour in older adults, but had no substantial effect for younger adults (Schwarzer and Renner 2000). Other studies confirmed that risk perceptions had a particular influence on motivation for physical activity in older adults (Renner et al. 2007).

It seems obvious that older people also perceive greater risks in absolute terms, given declining major biological systems and increasing objective prevalence for chronic diseases, accompanied by a rising priority for health (e.g., Ebner et al. 2006; Schindler and Staudinger 2008). Older people indeed perceive a heightened absolute risk for the development of cardiovascular diseases (Hamilton and Lobel 2012; Meischke et al. 2000; Renner et al. 2000, 2007), but show lower risk perceptions for stroke, diabetes, as well as breast and lung cancer compared to younger age groups (Adriaanse et al. 2008; Hamilton and Lobel 2012; Harwell et al. 2005). Albeit older people with a high body mass index perceive a higher risk of heart disease (e.g., Renner et al. 2000), a substantial proportion of - especially male-participants still disagreed that their heightened body weight was a health risk (Gregory et al. 2008). Since physical exercise is especially beneficial for cardiovascular health, the heightened risk perception in old age might help to boost motivation in this regard. Despite this, the mixed evidence leads over to the issue of biases that have been observed to influence people's subjective risk estimates.

Acknowledging that one's risk increases in old age does not necessarily imply that people become less optimistic about their risk in comparison with 
their peers. Unrealistic optimism was observed in middle-aged and older adults as well (Hamilton and Lobel 2012; Renner et al. 2000) and might be explained by increasing compensatory social downward comparisons in the face of experienced age-related declines (Bauer et al. 2008).

\subsection{Outcome Expectancies}

The value of the expected outcomes is essential in determining someone's readiness to act (e.g., Atkinson 1957). Having been established as a core concept in enabling behaviour change by Social Cognitive Theory, different labels like perceived benefit (Health Belief Model) or behavioural beliefs (Theory of Planned Behaviour) have been used (see Chap. 11).

The basic idea is that without the expectation of a resultant benefit, health behaviour lacks its justification, and consequently, the likelihood of disengagement increases. For example, people might agree that they could wear a helmet when riding a bicycle, but whether they decide to do so crucially depends on being convinced that wearing a helmet actually increases safety. Outcome expectancies have the form of if-then assumptions (like "If I engage in physical activity, then I will...") that refer to expected consequences of actions or behaviours that differ in the degree of desirability and probability (Bandura 2001; Heckhausen 1977). A thorough contemplation process with balancing of pros and cons of anticipated behavioural outcomes precedes the formation of outcome expectancies. Following a dynamic perspective, outcome expectancies are important for moving people from a pre-intending to an intending, that is, a pre-active stage of behaviour change (Schwarzer 2008). Outcome expectancies have been shown to translate threat appraisals and risk perceptions into action (see paragraph 13.6 on risk perceptions) and are an important mediator between self-efficacy beliefs and physical exercise (see Chap. 12; Gellert et al. 2012).

Classically, outcome expectancies ascribe value to an action due to presumed positive psychological effects (e.g., fun, relaxation, companionship), body image (e.g., appearance, self-image, confidence), or health benefits (Steinhardt and Dishman 1989; Schwarzer 2008). Outcome expectancies focusing on consequences closely tied to the behaviour itself are a better predictor of physical activity than distal ones. Specifically, affective expectations directly related to emotional states during or directly after physical activity affected intentions and behaviour in older adults (60-95 years) the most (Gellert et al. 2012). An age-tailored intervention targeting present orientation and emotional benefits of exercise together with components of goal 
attainment led to superior maintenance of physical activity in 60+ year-old adults (Gellert et al. 2014). The crucial importance of proximal, emotional outcome expectancies for physical activity enhancement in old age is substantiated by research on the role of affective attitudes (e.g., Conner et al. 2015) and fits with the idea of Socioemotional Selectivity Theory, assuming an increased focus on emotionally gratifying experiences in the here and now in older compared to younger age (e.g., Carstensen and Mikels 2005; see also Chaps. 12 and 14).

Adding to these findings, we recently demonstrated the importance of a positive dynamic through the actual fulfilment of outcome expectancies in the time course of exercise adoption and maintenance (Klusmann et al. 2016). Outcome expectancy fulfilment was the predominant predictor for differentiating between successful and unsuccessful behaviour changes and proximal outcome expectancies concerning emotional rewards were most meaningful in this regard. Outcome expectancies gain volitional relevance, especially if our expectations are met. Only then is it worth investing the effort; the behaviour change process is fuelled in terms of an upwards spiral (Loehr et al. 2014; Rothman 2000). An absence of desired outcomes, in contrast, results in a standstill, in which good intentions weaken or fade, and a sustainable change of habits becomes very unlikely.

Interestingly, in the above-mentioned study (Klusmann et al. 2016), older participants aged 60+ years were slightly less successful in their attempts to increase physical activity than younger adults. Higher age was associated with somewhat less endorsement of outcome expectancies and correspondingly fewer fulfilments.

\subsection{Practical Implications}

Remember our example from the beginning of the chapter: We were to realise that as long as central motivational requirements are unmet, any efforts to foster self-efficacy (see Chap. 12) or initiate volitional processes of behaviour change (see Chap. 14) seem premature and futile. Conversely, if our hypothetical person were to recognise the potentials of age and ageing and thus, were to have favourable self-perceptions of ageing, were to be convinced by the beneficial outcomes of physical activity, were to have an exercise identity, and were to be intrinsically motivated, a reasonable basis for health behaviour change could be established. In the following we will illustrate possible gateways for overcoming barriers and activating motivational resources for physical activity up to old age. 
Whether or not older adults identify as exercisers seems to crucially depend on the terminology used to describe physical activity. Older adults seem to use terms other than exercise-for example, "physically active"-to describe themselves (Whaley and Ebbeck 2002). Thus, the name of an exercise class could determine whether it aligns with older adults' identity and is well received within this age group (Hawley-Hague et al. 2016). Using the terms "exercise" or "falls prevention" could be a deterrent whereas "movement" may be more appealing; it may signal that the class is comprised of a variety of activities and that every participant will be able to find something suitable without having to self-identify as frail and at risk of falling (Nyman 2011).

Besides choosing appropriate names for activity programs aimed at older adults, creating an environment that fosters the integration of physical activity into older adults' identity can mean ensuring that social partners including health professionals express the opinion that physical activity is a life-long pursuit. Among regularly active older people, physical activity identity can develop further on its own as long as the older adults observe effects of their activity, for example, physical changes or feelings of achievement (see also paragraph 13.7 on outcome expectancies).

To increase the amount of favourable autonomous motivation, it seems advantageous to let participants take an active role in activity programs (cf. Ferrand et al. 2014) and to facilitate the development of a sense of togetherness or unity, for example, by explicitly supporting processes of group bonding, especially in women (Beck et al. 2010). However, one is well advised to also consider the risk of negative group dynamics, group members agreeing on "age-appropriate" sedentary behaviour, or people not fitting in.

For older people who already participate in an activity program, it seems useful to address subjective norms to increase their commitment (cf. Lucidi et al. 2006). However, subjective norms probably cannot prevent activity shortfalls, and it is more than doubtful whether tackling personal norms can stimulate newly adopted engagement.

The intriguing effects of favourable ageing self-perceptions boosting physical activity up to old age have taught us that taking means to support positive images of ageing will pay off. One can choose to directly combat negative age stereotypes through either correcting false beliefs or practising productive thinking (cf. Wolff et al. 2014). Alternatively, positive ageing perceptions might unobtrusively be strengthened by providing positive experiences with one's ageing body, helping people realise that fitness resources can be activated and that they are still powerful and capable (cf. Klusmann et al. 2012). Also, role models combating age stereotypes could be useful (Horton 2010). However, promoting master athletes entails the risk of older people's dis- 
identification. Role models should thus show characteristics as similar as possible to a peer of the target audience.

For risk communication, Renner and Schupp (2011) point out the following central principles: People should be informed about absolute risk using natural frequencies (conditional probabilities are hardly understood by both lay people and experts; Gigerenzer et al. 2008) as well as about the relative risk by comparing different hazards (to provide anchors for orientation and help people deal with both small numbers of probabilities and probabilities that exceed a 50-50 chance; Lipkus 2007; Weinstein 2000). To circumvent highrisk stereotypes that facilitate downward comparisons and negotiation of risk, recipients should be informed about their risk relative to similar others or receive personalised risk information (Hahn and Renner 1998; Harris et al. 2008; cf. Perloff and Fetzer 1986). Negative as well as positive feedback should be of high quality, since information conflicting with pre-existing risk perceptions is scrutinised carefully (Renner 2004). Finally, effective risk communication should disclose feasible ways to reduce risk and to increase healthy behaviour (Sheeran et al. 2014).

Maintenance problems of physical activity in old age might be overcome by fostering realistic outcome expectancies (Evers et al. 2012; Renner et al. 2012). Before starting to exercise, people mostly focus on the aversive beginning and thus underestimate enjoyment (Ruby et al. 2011). Expectancy adjustment might help people focus on accomplishable outcomes and make people see the attained outcomes that may reinforce behaviour change. Indeed, teaching exercise trainers strategies to promote positive emotions during exercise sessions increases adherence (Jekauc 2015) and, likewise, affective short-term messages produce higher levels of physical activity (Morris et al. 2015). A final note on a popular strategy: Broaching the issue of age-related physical limitations seems contraindicated in multiple ways. As we have come to know, it equally leads to higher levels of unfavourable controlled motivation and evokes less effective outcome expectancies.

\subsection{Conclusion}

Overall, the concepts introduced in this chapter have qualified as useful tools for understanding the activity of older adults and designing interventions to promote it. As is state-of-the-art in the health promotion profession, the development of effective interventions and programs is based on a thorough need and capacity assessment that considers the particular features of people and settings. With ageing, diversity of people increases; thus, there will hardly 
be any fixable one-fits-all approach to motivate older people for physical activity. Integrative approaches in which several concepts are combined to meet the specific needs of a target person or a target group of older people may be best.

\section{Suggested Further Reading}

- Gigerenzer, G., Gaissmaier, W., Kurz-Milcke, E., Schwartz, L.M., \& Woloshin, S. (2008). Helping doctors and patients make sense of health statistics. Psychological Science in the Public Interest, 8, 53-96.

- Meisner, B. A., Weir, P. L., \& Baker, J. (2013). The relationship between aging expectations and various modes of physical activity among aging adults. Psychology of Sport and Exercise, 14, 569-576.

- Strachan, S. M., Brawley, L. R., Spink, K., \& Glazebrook, K. (2010). Older adults' physically-active identity: Relationships between social cognitions, physical activity and satisfaction with life. Psychology of Sport and Exercise, 11(2), 114-121.

\section{References}

Adriaanse, M. C., Twisk, J. W., Dekker, J. M., Spijkerman, A. M., Nijpels, G., Heine, R. J., \& Snoek, F. J. (2008). Perceptions of risk in adults with a low or high risk profile of developing type 2 diabetes; A cross-sectional population-based study. Patient Education and Counseling, 73, 307-312.

Appleby, K. M., \& Dieffenbach, K. (2016). "Older and faster": Exploring elite masters cyclists' involvement in competitive sport. Sport Psychologist, 30, 13-23.

Atkinson, J. W. (1957). Motivational determinants of risk-taking behavior. Psychological Review, 64, 359-372.

Bandura, A. (2001). Social cognitive theory: An agentic perspective. Annual Review of Psychology, 52, 1-26.

Bauer, I., Wrosch, C., \& Jobin, J. (2008). I'm better off than most other people: The role of social comparisons for coping with regret in young adulthood and old age. Psychology and Aging, 23, 800-811.

Beck, F., Gillison, F., \& Standage, M. (2010). A theoretical investigation of the development of physical activity habits in retirement. British Journal of Health Psychology, 15, 663-679.

Brenes, G. A., Strube, M. J., \& Storandt, M. (1998). An application of the theory of planned behavior to exercise among older adults. Journal of Applied Social Psychology, 28, 2274-2290. 
Carstensen, L. L., \& Mikels, J. A. (2005). At the intersection of emotion and cognition: Aging and the positivity effect. Current Directions in Psychological Science, 14, 117-121.

Conner, M., McEachan, R., Taylor, N., O’Hara, J., \& Lawton, R. (2015). Role of affective attitudes and anticipated affective reactions in predicting health behaviors. Health Psychology, 34, 642-652.

Dean, R. N., Farrell, J. M., Kelley, M. L., Taylor, M. J., \& Rhodes, R. E. (2007). Testing the efficacy of the theory of planned behavior to explain strength training in older adults. Journal of Aging and Physical Activity, 15(1), 1-12.

Deci, E. L., \& Ryan, R. M. (2008). Self-determination theory: A macrotheory of human motivation, development, and health. Canadian Psychology, 49, 182-185.

Ditto, P. H. (2009). Passion, reason, and necessity a quantity-of-processing view of motivated reasoning. In T. Bayne \& J. Fernández (Eds.), Delusion and selfdeception: Affective and motivational influences on belief formation (pp. 23-53). New York: Psychology Press.

Ebner, N. C., Freund, A. M., \& Baltes, P. B. (2006). Developmental changes in personal goal orientation from young to late adulthood: From striving for gains to maintenance and prevention of losses. Psychology and Aging, 21, 664-678.

Evers, A., Klusmann, V., Ziegelmann, J. P., Schwarzer, R., \& Heuser, I. (2012). Long-term adherence to a physical activity intervention: The role of telephoneassisted vs. self-administered coping plans and strategy use. Psychology \& Health, 27, 784-797.

Ferrand, C., Nasarre, S., Hautier, C., \& Bonnefoy, M. (2012). Aging and well-being in French older adults regularly practicing physical activity: A self-determination perspective. Journal of Aging and Physical Activity, 20, 215-230.

Ferrand, C., Martinent, G., \& Bonnefoy, M. (2014). Exploring motivation for exercise and its relationship with health-related quality of life in adults aged 70 years and older. Ageing and Society, 34, 411-427.

Fischhoff, B., Bostrom, A., \& Quadrel, M. J. (2000). Risk perception and communication. In T. Connolly, H. R. Arkes, \& K. R. Hammond (Eds.), Judgment and decision making: An interdisciplinary reader (pp. 479-499). New York: Cambridge University Press.

Friederichs, S. A., Oenema, A., Bolman, C., \& Lechner, L. (2015). Long term effects of self-determination theory and motivational interviewing in a web-based physical activity intervention: Randomized controlled trial. International Journal of Behavioral Nutrition and Physical Activity, 12(1), 1-12.

Galea, M. N., \& Bray, S. R. (2006). Predicting walking intentions and exercise in individuals with intermittent claudication: An application of the theory of planned behavior. Rehabilitation Psychology, 51, 299-305.

Gamp, M., \& Renner, B. (2015). Experience-based health risk feedback and lack of reassurance. Health Psychology and Behavioral Medicine, 3, 410-423.

Gecas, V., \& Burke, P. J. (1995). Self and identity. In K. Cook, G. A. Fine, \& J. S. House (Eds.), Sociological perspectives in social psychology (pp. 41-67). Boston: Allyn \& Bacon. 
Gellert, P., Ziegelmann, J. P., \& Schwarzer, R. (2012). Affective and health-related outcome expectancies for physical activity in older adults. Psychology \& Health, 27, $816-828$.

Gellert, P., Ziegelmann, J. P., Krupka, S., Knoll, N., \& Schwarzer, R. (2014). An agetailored intervention sustains physical activity changes in older adults: A randomized controlled trial. International Journal of Behavioral Medicine, 21, 519-528.

Gigerenzer, G., Gaissmaier, W., Kurz-Milcke, E., Schwartz, L. M., \& Woloshin, S. (2008). Helping doctors and patients make sense of health statistics. Psychological Science in the Public Interest, 8, 53-96.

Gregory, C. O., Blanck, H. M., Gillespie, C., Maynard, L. M., \& Serdula, M. K. (2008). Perceived health risk of excess body weight among overweight and obese men and women: Differences by sex. Preventive Medicine, 47, 46-52.

Hahn, A., \& Renner, B. (1998). Perception of health risks: How smoker status affects defensive optimism. Anxiety, Stress and Coping, 11, 93-112.

Hamilton, J. G., \& Lobel, M. (2012). Passing years, changing fears? Conceptualizing and measuring risk perceptions for chronic disease in younger and middle-aged women. Journal of Behavioral Medicine, 35, 124-138.

Hamilton, J. G., \& Lobel, M. (2015). Psychosocial factors associated with risk perceptions for chronic diseases in younger and middle-aged women. Women Health, 55, 921-942.

Hardcastle, S., \& Taylor, A. H. (2005). Finding an exercise identity in an older body: "It's redefining yourself and working out who you are". Psychology of Sport and Exercise, 6, 173-188.

Harris, P. R., Griffin, D. W., \& Murray, S. (2008). Testing the limits of optimistic bias: Event and person moderators in a multilevel framework. Journal of Personality and Social Psychology, 95, 1225-1237.

Harwell, T. S., Blades, L. L., Oser, C. S., Dietrich, D. W., Okon, N. J., Rodriguez, D. V., et al. (2005). Perceived risk for developing stroke among older adults. Preventive Medicine, 41, 791-794.

Hawley-Hague, H., Horne, M., Skelton, D. A., \& Todd, C. (2016). Older adults' uptake and adherence to exercise classes. Journal of Aging and Physical Activity, 24, 119-128.

Heckhausen, H. (1977). Achievement motivation and its constructs: A cognitive model. Motivation and Emotion, 1, 283-329.

Helzer, E., \& Dunning, D. (2012). On motivated reasoning and self-belief. In S. Vazire \& T. D. Wilson (Eds.), Handbook of self-knowledge (pp. 379-396). New York: Guilford Press.

Horton, S. (2010). Masters athletes as role models? Combating stereotypes of aging. In J. Baker (Ed.), The masters athlete: Understanding the role of sport and exercise in optimizing aging (pp. 122-136). London: Routledge.

Jekauc, D. (2015). Enjoyment during exercise mediates the effects of an intervention on exercise adherence. Psychology, 6, 48-54. 
Klusmann, V., Evers, A., Schwarzer, R., \& Heuser, I. (2012). Views on aging and emotional benefits of physical activity: Effects of an exercise intervention in older women. Psychology of Sport and Exercise, 13, 236-242.

Klusmann, V., Musculus, L., Sproesser, G., \& Renner, B. (2016). Fulfilled emotional outcome expectancies enable successful adoption and maintenance of physical activity. Frontiers in Psychology, 6, 1990.

Koeneman, M. A., Verheijden, M. W., Chinapaw, M. J., \& Hopman-Rock, M. (2011). Determinants of physical activity and exercise in healthy older adults: A systematic review. International Journal of Behavioral Nutrition and Physical Activity, 8, 142.

Kotter-Grühn, D. (2015). Changing negative views of aging: Implications for intervention and translational research. Annual Review of Gerontology and Geriatrics, 35, 167-186.

Lee, M., Kim, M. J., Suh, D., Kim, J., Jo, E., \& Yoon, B. (2016). Feasibility of a selfdetermination theory-based exercise program in community-dwelling South Korean older adults: Experiences from a 13-month trial. Journal of Aging and Physical Activity, 24, 8-21.

Levy, B. R. (2009). Stereotype embodiment: A psychosocial approach to aging. Current Directions in Psychological Science, 18, 332-336.

Levy, B. R., \& Myers, L. M. (2004). Preventive health behaviors influenced by selfperceptions of aging. Preventive Medicine, 39, 625-629.

Levy, B. R., Slade, M. D., Kunkel, S. R., \& Kasl, S. V. (2002). Longevity increased by positive self-perceptions of aging. Journal of Personality and Social Psychology, 83, 261-270.

Levy, B. R., Pilver, C., Chung, P. H., \& Slade, M. D. (2014). Subliminal strengthening: Improving older individuals' physical function over time with an implicitage-stereotype intervention. Psychological Science, 25, 2127-2135.

Lipkus, I. M. (2007). Numeric, verbal, and visual formats of conveying health risks: Suggested best practices and future recommendations. Medical Decision Making, 27, 696-713.

Loehr, V. G., Baldwin, A. S., Rosenfield, D., \& Smits, J. A. (2014). Weekly variability in outcome expectations: Examining associations with related physical activity experiences during physical activity initiation. Journal of Health Psychology, 19, 1309-1319.

Lucidi, F., Grano, C., Barbaranelli, C., \& Violani, C. (2006). Social-cognitive determinants of physical activity attendance in older adults. Journal of Aging and Physical Activity, 14, 344-359.

Meischke, H., Sellers, D. E., Goff, D. C., Daya, M. R., Meshack, A., Taylor, J., \& Hand, M. M. (2000). Factors that influence personal perceptions of the risk of an acute myocardial infarction. Behavioral Medicine, 26, 4-13.

Meisner, B. A., Weir, P. L., \& Baker, J. (2013). The relationship between aging expectations and various modes of physical activity among aging adults. Psychology of Sport and Exercise, 14, 569-576. 
Miche, M., Brothers, A., Diehl, M., \& Wahl, H. W. (2015). Subjective aging and awareness of aging: Toward a new understanding of the aging self. Annual Review of Gerontology and Geriatrics, 35, 1-28.

Morris, B., Lawton, R., McEachan, R., Hurling, R., \& Conner, M. (2015). Changing self-reported physical activity using different types of affectively and cognitively framed health messages, in a student population. Psychology, Health \& Medicine, 2015, 1-10.

Mullen, S. P. (2011). Perceptions of change and certainty regarding the self-asexerciser: A multistudy report. Journal of Sport and Exercise Psychology, 33, 710-733.

Nusselder, W. J., Franco, O. H., Peeters, A., \& Mackenbach, J. P. (2009). Living healthier for longer: Comparative effects of three heart-healthy behaviors on life expectancy with and without cardiovascular disease. BMC Public Health, 9, 487.

Nyman, S. R. (2011). Psychosocial issues in engaging older people with physical activity interventions for the prevention of falls. Canadian Journal on Aging, 30, $45-55$.

Perloff, L. S., \& Fetzer, B. K. (1986). Self-other judgments and perceived vulnerability to victimization. Journal of Personality and Social Psychology, 50, 502-510.

Renner, B. (2004). Biased reasoning: Adaptive responses to health risk feedback. Personality and Social Psychology Bulletin, 30, 384-396.

Renner, B., \& Schupp, H. (2011). The perception of health risks. In H. Friedman (Ed.), The Oxford handbook of health psychology (pp. 637-665). New York: Oxford University Press.

Renner, B., Knoll, N., \& Schwarzer, R. (2000). Age and body weight make a difference in optimistic health beliefs and nutrition behaviors. International Journal of Behavioral Medicine, 7, 143-159.

Renner, B., Spivak, Y., Kwon, S., \& Schwarzer, R. (2007). Does age make a difference? Predicting physical activity of South Koreans. Psychology and Aging, 22, 482-493.

Renner, B., Hankonen, N., Ghisletta, P., \& Absetz, P. (2012). Dynamic psychologi$\mathrm{cal}$ and behavioral changes in the adoption and maintenance of exercise. Health Psychology, 31, 306-315.

Rhodes, R. E., Kaushal, N., \& Quinlan, A. (2016). Is physical activity a part of who I am? A review and meta-analysis of identity, schema and physical activity. Health Psychology Review, 10, 204-225.

Rothman, A. J. (2000). Toward a theory-based analysis of behavioral maintenance. Health Psychology, 19, 64-69.

Ruby, M. B., Dunn, E. W., Perrino, A., Gillis, R., \& Viel, S. (2011). The invisible benefits of exercise. Health Psychology, 30, 67-74.

Sarkisian, C. A., Prohaska, T. R., Wong, M. D., Hirsch, S., \& Mangione, C. M. (2005). The relationship between expectations for aging and physical activity among older adults. Journal of General Internal Medicine, 20, 911-915. 
Schindler, I., \& Staudinger, U. M. (2008). Obligatory and optional personal life investments in old and very old age: Validation and functional relations. Motivation and Emotion, 32, 23-36.

Schwarzer, R. (2008). Modeling health behavior change: How to predict and modify the adoption and maintenance of health behaviors. Applied Psychology, 57, 1-29.

Schwarzer, R., \& Renner, B. (2000). Social-cognitive predictors of health behavior: Action self-efficacy and coping self-efficacy. Health Psychology, 19, 487-495.

Sheeran, P., Harris, P. R., \& Epton, T. (2014). Does heightening risk appraisals change people's intentions and behavior? A meta-analysis of experimental studies. Psychological Bulletin, 140, 511-543.

Slovic, P. (1987). Perception of risk. Science, 236, 280-285.

Slovic, P. (2000). The perception of risk. London: Earthscan Publications.

Slovic, P., \& Peters, E. (2006). Risk perception and affect. Current Directions in Psychological Science, 15, 322.

Slovic, P., Peters, E., Finucane, M., \& MacGregor, D. G. (2005). Affect, risk, and decision making. Health Psychology, 24, 35-40.

Solberg, P. A., Hopkins, W. G., Ommundsen, Y., \& Halvari, H. (2012). Effects of three training types on vitality among older adults: A self-determination theory perspective. Psychology of Sport and Exercise, 13, 407-417.

Steinhardt, M. A., \& Dishman, R. K. (1989). Reliability and validity of expected outcomes and barriers for habitual physical activity. Journal of Occupational Medicine, 31, 536-546.

Stets, J. E., \& Burke, P. J. (2003). A sociological approach to self and identity. In M. R. Leary \& J. P. Tangney (Eds.), Handbook of self and identity (pp. 128-152). New York: Guilford Press.

Strachan, S. M., Brawley, L. R., Spink, K., \& Glazebrook, K. (2010). Older adults' physically-active identity: Relationships between social cognitions, physical activity and satisfaction with life. Psychology of Sport and Exercise, 11, 114-121.

Stretcher, V. J., Champion, V. L., \& Rosenstock, I. M. (1997). The health belief model and health behavior. In D. S. Goschman (Ed.), Handbook of health behavior research (Vol. 1, pp. 71-91). New York: Plenum Press.

Vallance, J. K., Murray, T. C., Johnson, S. T., \& Elavsky, S. (2011). Understanding physical activity intentions and behavior in postmenopausal women: An application of the theory of planned behavior. International Journal of Behavioral Medicine, 18, 139-149.

Van 't Riet, J., \& Ruiter, R. A. C. (2013). Defensive reactions to health-promoting information: An overview and implications for future research. Health Psychology Review, 7, 104-136.

van der Pligt, J. (1998). Perceived risk and vulnerability as predictors of precautionary behaviour. British Journal of Health Psychology, 3, 1-14.

Van Hoecke, A. S., Delecluse, C., Bogaerts, A., \& Boen, F. (2014). The long-term effectiveness of need-supportive physical activity counseling compared with a standard referral in sedentary older adults. Journal of Aging and Physical Activity, 22, 186-198. 
Weinstein, N. D. (2000). Perceived probability, perceived severity, and healthprotective behavior. Health Psychology, 19, 65-74.

Whaley, D. E., \& Ebbeck, V. (2002). Self-schemata and exercise identity in older adults. Journal of Aging and Physical Activity, 10, 245-259.

Wolff, J. K., Warner, L. M., Ziegelmann, J. P., \& Wurm, S. (2014). What do targeting positive views on ageing add to a physical activity intervention in older adults? Results from a randomised controlled trial. Psychology \& Health, 29, 915-932.

Wurm, S., Tomasik, M. J., \& Tesch-Römer, C. (2010). On the importance of a positive view on ageing for physical exercise among middle-aged and older adults: Cross-sectional and longitudinal findings. Psychology \& Health, 25, 25-42.

Wurm, S., Warner, L. M., Ziegelmann, J. P., Wolff, J. K., \& Schüz, B. (2013). How do negative self-perceptions of aging become a self-fulfilling prophecy? Psychology and Aging, 28, 1088-1097. 